\title{
CINEMA E EDUCAÇÃO: OS FILMES E O ENSINO DE HISTÓRIA NA EDUCAÇÃO BÁSICA MUNICIPAL DE ARACAJU
}

\author{
CINEMA NA EDUCATION: FILMES AND THE TEACHING OF \\ HISTORY IN THE MUNICIPAL BASIC EDUCATION OF ARACAJU
}

\author{
Daniel Bramo Nascimento de Carvalho \\ Mestre em Educação, Universidade Tiradentes-UNIT \\ Aracaju, Sergipe- Brasil \\ historiadobramo@gmail.com \\ Ronaldo Nunes Linhares \\ Doutor em Ciências da Comunicação, Universidade de São Paulo- USP \\ Aracaju, Sergipe- Brasil \\ nuneslinhares.ronaldo8@gmail.com
}

\begin{abstract}
Resumo: O presente texto trata das formas de apropriação por parte dos professores, das sugestões de filmes propostas nos livros didáticos de his tória utilizados entre o $6^{\circ}$ e o $9^{\circ}$ do ensino fundamental anos finais, nas práticas docentes na rede pública de ensino do município de Aracaju, Sergipe, Brasil. É fruto de uma pesquisa aplicada, do tipo estudo de caso, envolvendo 20 escolas da rede de educação municipal como "locus" reconhecendo a exis tência de múltiplas realidades dentro de uma mesma rede de educação. De abordagem qualitativa, o levantamento de informações ocorreu por meio de aplicação de questionário misto com 26 professores e, entrevistas objetivando o aprofundamento das questões abertas, com 10 professores. Os resultados mostram que na rede, nove coleções diferentes são utilizadas para a disciplina de história, em que 92\% dos/as professores afirmam conhecer as sugestões dos livros, mas apenas $30 \%$ fazem um uso significativo em sala de aula, de tal modo que não conseguem abranger um uso mais efetivo dos dispositivos fílmicos em sala de aula. Desta forma, conclui-se que é necessário atentar mais para as possiblidades que as produções cinematográficas podem oferecer para a educação, afirmando a sua importância para a formação básica intelectual e sociocultural dos sujeitos alunos.
\end{abstract}

Palavras-chave: Filmes. His tória. Livro didático. Educação básica.

\begin{abstract}
This text deals with the forms of appropriation, on the part of the teachers, of the suggestions of films proposed in the history textbooks, used between the 6th and 9th years of elementary school, in the teaching practices in the public school system of the municipality of Aracaju, Sergipe, Brazil. It is the result of applied research, of the case study type, involving 20 schools in the municipal education network as "locus" recognizing the existence of multiple realities within the same education network. With a qualitative approach, the gathering of information took place through the application of a mixed questionnaire with 26 teachers and interviews aiming to deepen the open questions, with 10 teachers. The results show that in the network, nine differe nt collections are used for the history discipline, in which $92 \%$ of the teachers claim to know the suggestions of the books, but only $30 \%$ make a significant use in the classroom, in such a way. so that they cannot cover a more effective use of film devices in the classroom. Thus, it is concluded that it is necessary to pay more attention to the possibilities that cinematographic productions can offer for education, affirming its importance for the basic intellectual and socio cultural formation of the student subjects.
\end{abstract}

Keywords: Movies. History. Textbooks. Basic Education.

Para citar - (ABNT NBR 6023:2018)

CARVALHO, Daniel Bramo Nascimento de; LINHARES, Ronaldo Nunes. Cinema e educação: os filmes e o ensino de história na educação básica municipal de Aracaju. Eccos - Revista Cientifica, São Paulo, n. 53, p. 1-21, e16454, abr./jun. 2020. Dis ponível em: https://doi.org/10.5585/eccos.n53.16454. 


\section{Introdução}

Importante fonte histórica e de documentação, o cinema vem sendo utilizado na formação de professores enquanto reconstituição da narrativa histórica ou reafirmação/complementação do conteúdo em sala de aula (CARVALHO, ANDRADE, LINHARES, LIMA \& FREIRE, 2015). Os resultados deste estudo demonstraram que o uso do cinema enquanto dispositivo pedagógico na formação do futuro professor de história não contempla as amplas possiblidades que o cinema possui enquanto arte, linguagem, documento, mídia e produto cultural e, que pode contribuir na educação, tanto na formação do aluno como na do professor.

É interessante tomarmos consciência da importância que os filmes possuem na formação do sujeito, não apenas intelectual, mas também na formação crítica, cidadã e cultural. Os avanços tecnológicos e midiáticos com a televisão, vídeo cassete, aparelhos DVD e hoje com computadores, aparelhos portáteis e o acesso à internet, facilitam o acesso a filmes de forma rápida e prática em diferentes lugares e plataformas digitais. Portanto, é preciso refletir sobre as práticas em sala de aula e a presença de diferentes mídias na formação do sujeito.

É de suma importância a leitura e o aprendizado que diversos livros nos proporcionam ao longo de nossa formação. É perceptível o significado que possui em nossa sociedade (BRIGGS E BURKE, 2006). No entanto, isso não deve descaracterizar a contribuição de outras fontes de informação, formas de narrativas e de comunicação como os filmes. Segundo Duarte (2009), o hábito de ver filmes é tão importante quanto a leitura de obras literárias na formação do sujeito e, que o professor enquanto agente no processo de socialização, precisa repensar suas práticas docentes, refletindo sobre as possiblidades que o filme pode oferecer a sua docência.

Atentar para esses processos de comunicação e informação é justamente atribuir importância aos filmes na educação. O livro e o filme são mídias completamente diferentes e que surgem em tempos e sociedades distintas, mas a intenção de comunicar é a mesma, o que os caracterizam como agentes socioculturais na formação do sujeito (SETTON, 2009).

Mesmo que o filme facilite a imaginação, sua intenção é de contar uma história ou de transmitir uma mensagem muito próxima dos objetivos do livro. Com a imagem, junto ao som e movimento, possibilitam visualizar a construção de vivências de outras sociedades, tempos e realidades. Assim, ocupam um importante espaço nas práticas socioculturais, participando da formação cultural do sujeito para além de instituições como: a escola, a família, a igreja dentre outras. Aborda em suas narrativas as condições necessárias para criação de formas e sentidos 
que expressam a sociedade contemporânea, esta dominada pela imagem em movimento (SETTON, 2010). Livros, filmes, Televisão e outras mídias devem ser vistos também como bens culturais de sociedade capitalista, como forma de consumo intrínseca ao entretenimento (LIPOVESTSKY, 2010).

É preciso contextualizar o lugar dessas duas mídias em uma sociedade capitalista, baseada no consumo de produtos, informação, entretenimento e, que seu crescimento reforça a transformação de bens culturais em bens comerciais. Integrar melhor o seu uso nas práticas docentes e ampliar as possibilidades das mídias na educação e na formação sociocultural é um importante passo para que se alfabetize o sujeito de forma crítica e autônoma na sociedade da imagem.

Assim, o presente texto busca analisar as sugestões de filmes presentes nos livros didáticos de história, utilizados entre o $6^{\circ}$ e $9^{\circ}$ do ensino fundamental maior. Os livros analisados foram selecionados pela rede pública de ensino do município de Aracaju/SE, Brasil. Compreendendo o espaço que os filmes possuem na sociedade contemporânea, é possível tentarmos compreender as possiblidades que possuem no contexto da educação básica e, como podem contribuir para o desenvolvimento crítico diante das questões históricas presentes no currículo escolar.

\section{Comunicação, cinema e educação}

Não é de agora que o filme faz parte do cotidiano dos sujeitos e de nossa sociedade. Desde sua primeira aparição na França, em 1895, o filme compõe o cenário do dia a dia do sujeito que o coloca em seus planejamentos de diversas atividades. Filmando primeiramente ações do dia a dia de homens e mulheres, o filme nunca deixou de se transformar. Interagindo cada vez mais, saiu das salas escuras e entrou em nossas casas, hoje levamos os filmes conosco em nossos bolsos, permitindo que a experiência filmica estenda-se em diferentes ambientes.

Isso proporciona para a educação o encontro de um forte aliado a suas práticas de ensino e construção de situações que permitam que o aluno compreenda melhor as questões postas pela escola. Alguns discursos promovidos em sala de aula podem parecer distante da realidade e, o filme pode contribuir para que ocorra a aproximação entre aluno, conteúdo, professor e aprendizagem.

Assistir filmes faz parte da nossa cultura. São diversas as plataformas e canais de veiculação que permitem acessar as diferentes narrativas audiovisuais. Seja pelos canais de televisão aberta ou fechada, internet ou serviços de streamings e, até frequentando salas de 
cinema, alunos e professores assistem filmes. Inserir esses produtos no contexto da educação básica é inserir experiências da realidade vivida pelo aluno fora da escola e mediar o processo de aprendizado (MACHADO, 2015).

O que podemos notar é que os meios de comunicação permitem outras formas de ler e interpretar o mundo. Com o filme, desenvolveu-se outras formas de capturar e registrar os comportamentos sociais, as mudanças do homem em seu meio e a construção de narrativas. Possuindo uma linguagem própria e única, o cinema é a arte que consagra todas as outras. Proporciona ao telespectador uma imersão dos sentidos, tanto humanos-visão e audição- quanto simbólicos-signo e significado. É uma linguagem universal, que fala para todos.

Se a educação atual preocupa-se com a entrega de conteúdos e, que o aluno domine elementos de uma formação intelectual, a necessidade de uma formação que contemple os modos de relação com os meios de comunicação pode promover uma melhor interação crítica com os conteúdos curriculares e midiáticos. E não devemos trabalhar para produzir esses meios para a educação, eles já estão prontos e postos na sociedade.

Antes de chegar na escola, diversas são as experiências que se adquire relacionando-se tanto com os meios de comunicação quanto com o meio sociocultural. A escola não é o primeiro contato com o conhecimento que o aluno tem e, não podemos negar e esquecer esses encontros proporcionados na interação pré-escolar.

O que levamos em consideração aqui é que devemos encarar os meios de comunic ação tais como são, um produto da cultura e identificar em suas estruturas as contribuições que nos podem oferecer para formar o aluno com maior competência para o meio social. Refletir sobre os meios de comunicação na educação, com foco nos filmes, ampliam o processo comunicativo entre aluno e professor (MACHADO, 2015). Aqui, o professor torna-se o principal agente mobilizador no processo de aprendizagem do aluno. A decisão final de usar ou não os meios de comunicação, mídias e tecnologias em sala de aula ainda é do professor, mesmo o aluno tendo acesso a esses materiais fora da escola.

Já o livro didático, temos em 1985 o Programa Nacional do Livro Didático (PNLD) que passa a atuar na distribuição dos livros didáticos no Brasil. É através do PNLD que o livro chega e assume seu espaço no meio escolar, influenciado de forma direta nas práticas docentes e nas metodologias de ensino e aprendizagem de alunos e professores das escolas públicas brasileiras. É no PNLD de 2014 que se firma a prática de sugestões de mídias para a educação básica (filmes, sites, livros, músicas, jogos eletrônicos, etc.).

No entanto, a política de sugestão de filmes nos livros didáticos é apenas um dos meios que se buscou a inclusão de mídias e tecnologias digitais, tanto nas escolas quanto em sala de 
aula. Muitos outros projetos foram idealizados e executados por todo o país entre os séculos XX e XXI, pensando em como os meios de comunicação, as tecnologias e mídias digita is poderiam contribuir para a prática docente e para o desenvolvimento crítico dos alunos.

Em 1927, o uso do cinema nas escolas já era concebido, sendo concretizado em 1937 pela criação do Instituto Nacional do Cinema Educativo (INCE) no governo Getúlio Vargas (1930-1945), atuando até 1966. Na década de 1980, com o advento do aparelho televisivo, os meios de comunicação voltam a ser destaque nas reflexões que a educação produzia em referência as metodologias que seriam executadas nas escolas brasileiras.

Nos anos da década de 1980, destacamos o Projeto Vídeo Escola como um importante movimento que pensou no uso do audiovisual nas escolas. Segundo Nunes (2015) foi um dos primeiros Projetos/Programas que havia pensado a contemplação do uso do audiovisual na educação, já em 1989. Sua primeira fase, foi implantada na educação privada como piloto, em escolas da região Sul e Sudeste do Brasil, resultando em experiências e reflexões no que diz respeito ao uso do audiovisual em sala de aula. O objetivo do projeto era fazer com que os professores se apropriassem do que a indústria cultural produzia para o desenvolvimento de suas metodologias e planos de ensino (LINHARES, 2007).A Fundação Roberto Marinho (FRM) e a Fundação do Banco do Brasil (FBB) além de financiar toda a execução do projeto, fiscalizavam e cobravam resultados das escolas que recebiam os kits.

Sergipe participou do Projeto Vídeo Escola, entre os anos de 1989/96. O estado recebeu 100 aparelhos de TV com vídeo cassete e kits de filmes que foram distribuídos para 100 escolas, distribuídas em 64 municípios, ampliados em 1992 para 68 municípios (NUNES, 2015). Em sua pesquisa Nunes (2015) destaca a ampliação do projeto para atender a rede de ensino municipal de Aracaju.

A década de 1990 foi um período de movimentação no que diz respeito ao uso dos meios de comunicação, tecnologias e mídias digitais. Seguindo o âmbito nacional, o estado de Sergipe teve implantado 3 importantes projetos que idealizavam e inseriam as tecnologias na escola. Ainda segundo Nunes (2015), o primeiro projeto fazia referência ao uso da informática na escola, fruto do Projeto Educom. O segundo foi o Projeto Vídeo Escola, já descrito acima como práticas do uso de filmes nas escolas. E o terceiro chamado de Salto para o Futuro que visou priorizar o uso da televisão, no entanto, contemplava outros recursos tais como fax e internet e também tratava da formação docente.

Assim percebemos que o livro didático não é o primeiro meio utilizado que buscou inserir outros meios de comunicação, tecnologias ou mídias digitais para além do próprio livro. Enquanto mídia, sempre ocupou um espaço importante no âmbito escolar e ainda possui grande 
influência no momento de decisão do docente quanto ao que vai ser tratado durante o período letivo.

O que destacamos aqui, é que através do livro didático, filmes e outras mídias estão sendo sugeridas para uso no espaço escolar atualmente. Assim, a questão aqui posta considera como pressuposto que a utilização ou não das sugestões das mídias e filmes na escola, depende exclusivamente do professor, que decide se o filme contempla a sua atividade e se é ou não exibido. Desta forma, o professor torna-se o principal agente mobilizador nas práticas de uso do audiovisual, pois é quem está à frente do desenvolvimento pedagógico das aulas.

Figura 01 - Competências da BNCC que envolvem Tecnologias Digitais da informação e Comunicação

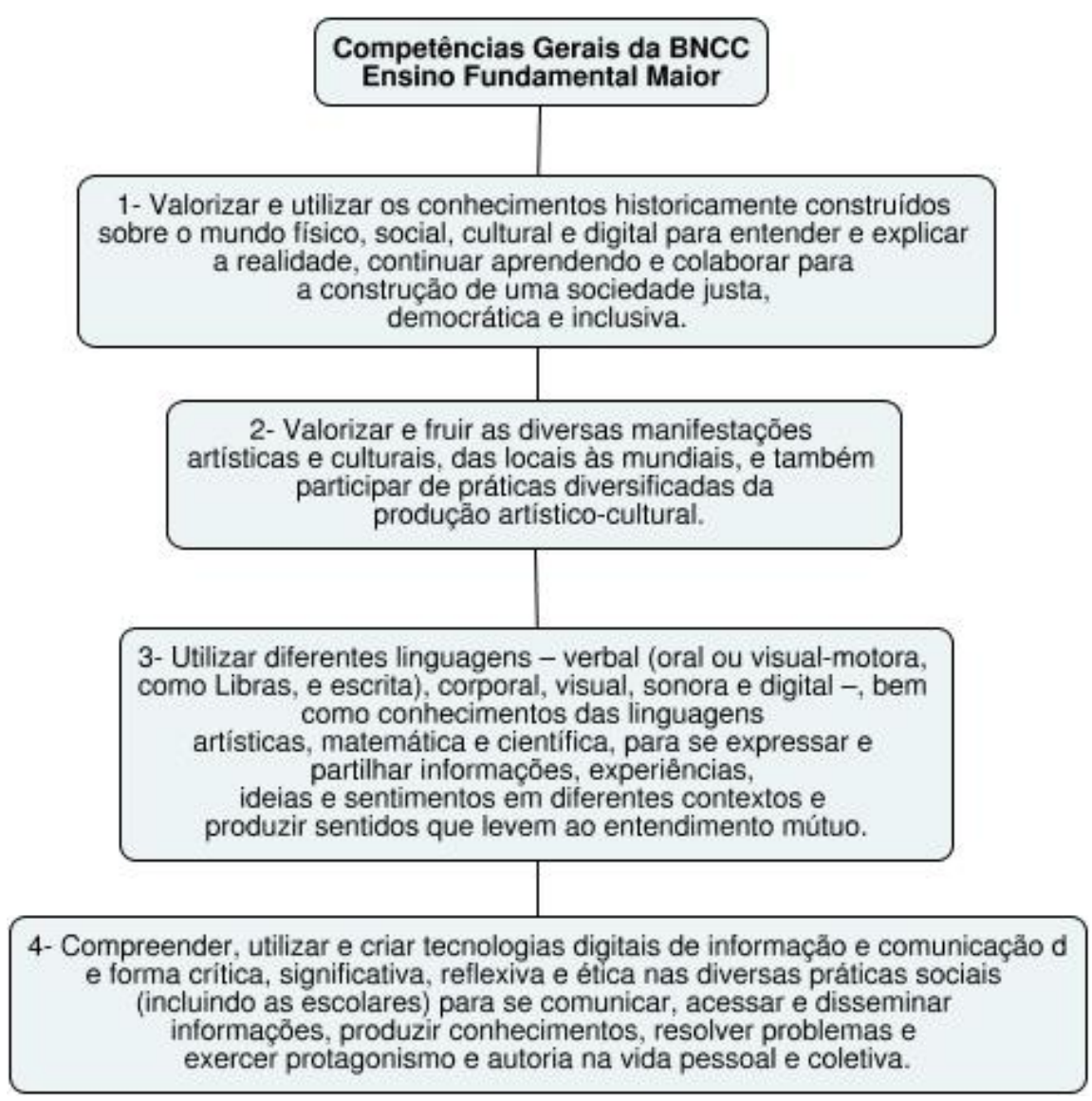

Fonte: Adaptado BNCC (2019).

As quatro competências mostram que os órgãos responsáveis pela educação no país preocupam-se em como os meios de comunicação digitais podem contribuir no processo cognitivo do aluno. Reforça a necessidade que a educação tem de incluir estes meios nos 
processos de ensino e aprendizagem e compreensão não só da ciência, mas também, das especificidades do mundo vivido.

A primeira e segunda competência direciona o olhar do professor para uma valorização dos conhecimentos gerados no campo cultural e digital, duas áreas intrínsecas as sugestões de filmes presentes no livro didático e sobre as manifestações artísticas e culturais. Já a terceira remete a utilização das diferentes linguagens em sala de aula no compartilhamento das informações, experiências, ideias e sentimentos para a produção de um entendimento mútuo, dentre elas a linguagem visual, sonoro e digital. A quarta propõe a compreensão, utilização e criação de tecnologias digitais da informação e comunicação de forma crítica tanto no acesso a tais informações quanto na produção de conhecimentos.

Com ênfase na segunda competência, ela pode ser interpretada de várias maneiras, desde as manifestações de cunhos populares como danças, comidas típicas, rituais, etc. até as manifestações no campo audiovisual. É interessante pensarmos o filme enquanto produto artístico cultural e inseri-lo na sala de aula. A própria BNCC em suas competências gerais para a educação demonstra as inúmeras possibilidades formativas que o filme pode agregar no processo de formação do sujeito.

É deste modo que a BNCC caracteriza-se como documento fundamental para a educação, pois além de estabelecer as competências descritas, reafirma a importância e necessidade de olharmos para os meios de comunicação, tecnologias e mídias digitais que compõem o cenário de formação dos alunos na educação básica. Percebemos então que o livro didático não é o único a contribuir para a inserção dos filmes na escola, a BNCC também colabora a partir do momento que determina quais competências os alunos devem construir em sua formação intelectual e enquanto sujeito.

\section{A pesquisa e seus resultados}

O lócus deste estudo foram as escolas da rede pública municipal de educação de Aracaju. Segundo Santos (2017), a rede de ensino conta com 73 escolas municipais, divididas em; 33 unidades de Escola Municipal de Educação Infantil (EMEI) e 40 unidades de Escola Municipal de Ensino Fundamental (EMEF). Das 40 unidades de ensino que são EMEF, 50\% correspondem ao Ensino Fundamental Anos Iniciais ( $1^{\circ}$ ao $5^{\circ}$ ano $)$ e os outros $50 \%$ ao Ensino Fundamental Ano Finais ( $6^{\circ}$ ao $9^{\circ}$ ano). 
O trabalho documental com os livros didáticos de história do $6^{\circ}$ ao $9^{\circ}$ ano deu-se por corresponder as séries que já trabahham com a figura de um professor licenciado por conteúdo disciplinar. O estudo assim, delimita-se na educação básica do Ensino Fundamental Anos Finais, sob a responsabilidade dos municípios. A escolha da rede municipal de Aracaju dá-se por proximidade geográfica, o que permitiu aplicação pessoal tanto dos questionários como das entrevistas, o que também permitiu o contato com os livros didáticos utilizados pelos/as professores/as em toda a rede de ensino.

De abordagem qualitativa (MINAYO, 2016), o estudo analisa um caso concreto, procedendo de acordo com as percepções que os professores têm das suas práticas em sala de aula. Destacamos o conhecimento que é socialmente construído a partir das interações cotidianas dos sujeitos participantes desta pesquisa (ANDRÉ, 2013), alterando a realidade em que atuam. De objetivo descritivo, reúne informações detalhadas e sistemáticas a respeito da percepção dos/as professores/as sobre a contribuição das sugestões de filmes, descrevendo o fenômeno inserido no contexto escolar bem como as possiblidades didáticas e a contribuição para a prática docente (MEIRINHOS E OSÓRIO, 2010).

Como estudo de caso, permitiu dividir a investigação em três momentos ancorados em André (2013). Primeiro o exploratório, ao qual delimitamos o foco do estudo nas sugestões de filmes nos livros didáticos de história. Segundo, a coleta de dados, obtendo os livros e aplicação dos instrumentos de pesquisa para a obtenção das informações necessárias para a discussão. E terceiro, a discussão sistemática dos dados reunidos, podendo compreender como ocorre a prática docente no uso dos filmes nas aulas de história.

O uso das sugestões de filmes dos livros didáticos é a questão problema deste estudo. Para tentar responder aos objetivos, optamos pelo estudo de caso como procedimento (YIN, 2005), pois reúne professores/as de uma modalidade de ensino, em um contexto específico na Rede municipal na disciplina de História, possibilitando o confronto dos dados de um mesmo objeto de pesquisa (OLIVEIRA, 2008).

A coleta de informações e dados ocorreu em 20 escolas da rede, com 41 professores/as de história. Assim, 26 professores responderam ao questionário misto (presencialmente), com 25 questões (17 objetivas e 8 subjetivas) e realizamos uma entrevista semi-estruturada com 10 professores/as, que aceitaram participar desta etapa da pesquisa, contendo 10 questões abertas realizadas por vezes nas casas dos professores por outras nas escolas em que atuam.

Após o planejamento operacional, realizamos um levantamento dos livros didáticos utilizados pela rede. A Secretária Municipal da Educação de Aracaju (SEMED) forneceu os dados sobre as escolas e quais coleções cada unidade tinha adquirido por meio do PNLD. Na 
planilha constava o nome da coleção e escola que a haviam selecionado. O levantamento permitiu aferir quais seriam as escolas que participariam da devida investigação.

No segundo momento, aplicamos o questionário com questões acerca do consumo de mídia no dia a dia (frequência que ver filmes, espaços culturais frequentados, etc.) e quais mídias utilizavam durante a prática docente (livros, jornais, músicas, filmes, entre outros) para identificar os hábitos de consumo midiático dos/as professor/as. O questionário permitiu-nos identificar o quanto os/as professores/as de história utilizavam as sugestões de filmes dos livros didáticos, possibilitando assim, nos aprofundar melhor no que se refere as suas práticas docentes com os filmes em sala de aula.

A partir destas informações, propomos aos 26 professores uma entrevista como instrumento para ampliar e aprofundar as informações sobre o uso das sugestões em sala de aula. 10 professores participaram das entrevistas. Neste momento, pudemos aprofundar questões sobre a importância do livro didático nas práticas de ensino, as contribuições das sugestões de filmes nos livros e, as considerações e procedimentos metodológicos no uso do filme.

Por fim, organizamos as falas e desenvolvemos uma discussão com base na técnica proposta por Bardin (2016), de onde identificamos as convergências e divergências entre as falas e destas com a literatura, articulando-os com as seguintes categorias: Uso das Sugestões de Filmes; Uso dos Filmes em sala de aula; Temas dos Filmes; Formas de Abordagem do Filme em sala de aula e; Planejamento da Aula com o Filme.

As categorias elencadas para o estudo têm por objetivo orientar a discussão sobre as metodologias de uso dos filmes pelos/as professores/as participantes da pesquisa. Desta forma, os referenciais teóricos e pressupostos que norteiam a pesquisa, compõem um quadro de discussão consistente que buscam dentro da metodologia aplicada descrever e discutir as múltiplas dimensões a partir da reconstrução de processos e relações que constituem a experiência docente cotidiana (ANDRÉ, 2013).

O processo de codificação dos dados foi suportado pelo software de análise qualitativa webQDA. Segundo Costa e Amado (2018) o software permite que pesquisadores de diversas áreas organizem seus dados ditos qualitativos de forma sistemática, possibilitando melhor visualização das informações coletadas durante a pesquisa, comportando um grande número de dados referente ao objeto estudado pelos investigadores, além de permitir a colaboração de outros sujeitos com o tratamento dos dados.

Constatamos em levantamento, sete coleções diferentes dos $6^{\circ}$ ao $9^{\circ}$ ano nas escolas que trabalham com o Ensino Fundamental Maior, como demonstramos no quadro 01. Ao ter 
conhecimento de quais coleções cada unidade de ensino estava usando, procuramos obtê-las para análise das sugestões.

Quadro 01 - Coleções adquiridas por cada escola

\begin{tabular}{|c|c|c|c|}
\hline Titulo & Autor & Editora & Núme ro de Escola \\
\hline $\begin{array}{l}\text { Estudar História: Das } \\
\text { origens do homem à era } \\
\text { digital }\end{array}$ & Patrícia Ramos Braick & Moderna & 03 \\
\hline História nos dias de hoje & $\begin{array}{l}\text { Flávio de Campos } \\
\text { Regina Claro } \\
\text { Miriam Dolhnikoff }\end{array}$ & Leya & 02 \\
\hline $\begin{array}{l}\text { História Sociedade e } \\
\text { Cidadania }\end{array}$ & Alfredo Boulos Junior & FDT & 07 \\
\hline Historiar & $\begin{array}{l}\text { Gilberto Cotrim e } \\
\text { Jaime Rodrigues }\end{array}$ & Saraiva & 01 \\
\hline Projeto Araribá & Obra Coletiva & Moderna & 01 \\
\hline Projeto Radix & Cláudio Vicentino & Scipione & 01 \\
\hline Projeto Teláris História & $\begin{array}{l}\text { Gislane Azevedo } \\
\text { Reinaldo Seriacopi }\end{array}$ & Ática & 01 \\
\hline Vontade de Saber História & $\begin{array}{l}\text { Marco Pellegrini, } \\
\text { Adriana Dias e Keila } \\
\text { Grinberg }\end{array}$ & FDT & 04 \\
\hline
\end{tabular}

Fonte: Dados obtidos junto a Secretária Municipal da Educação de Aracaju (SEMED) (2018).

Para análise dos dados obtidos nas entrevistas, utilizamos o software de análise qualitativa WebQDA. O software nos auxiliou no tratamento dos dados e no ordenamento das informações nas seguintes categorias; Uso das Sugestões de Filmes; Uso dos Filmes em sala de aula; Tipos de Filmes; Gêneros e Temas dos Filmes; Formas de Abordagem do Filme em sala de aula e; Planejamento da Aula com o Filme.

\subsection{Sobre os resultados - as sugestões no livro didático}

É importante descrever como as sugestões aparecem nos livros didáticos para compreender como o professor faz uso destas sugestões em sua prática docente. O PNLD2014 apenas estabeleceu os critérios para que as obras apresentassem sugestões de tecnologias e mídias digitais para apoiar o processo de ensino e aprendizagem para professores e alunos, não determinou um modelo estrutural para as editoras seguirem. Esta postura deu liberdade para que as editoras organizassem da maneira que achavam melhor a ordem de conteúdo e sugestões. 
Nas coleções "História, Sociedade e Cidadania", "História nos dias de hoje", "Historiar", "Estudar história: das origens do homem à era digital" e "Projeto Radix" trazem suas sugestões ao final de cada capitulo. A coleção "Vontade de saber história" adotou a metodologia de sugestões em meio ao conteúdo abordado durante os capítulos. A coleção "Araribá" apresenta sugestões tanto em meios aos conteúdos quanto aos finais do capitulo, no entanto, as sugestões aos finais do capitulo nesta coleção são mais aprofundadas e tratadas para facilitar a prática docente. Todas estas coleções oferecem sugestões para professores e aluno, já a coleção "Telaris" apresenta apenas no material didático do professor localizado ao final do livro.

Percebemos que os docentes conhecem o livro didático que usa em sala de aula, pois apenas $8 \%$ não tinham conhecimento das sugestões. Conhecer as sugestões e sua relação com o conteúdo é o primeiro passo para que o professor decida ou não utilizar em sala de aula. Os professores reconhecem a importância que as sugestões possuem para a prática docente e sua contribuição ao processo de aprendizagem e sua conexão com os conteúdos propostos nos livros.

\footnotetext{
Ele traz essa grande contribuição pra (sic) minha prática docente, principalmente indicando várias coisas como eu falei anteriormente, indicando filme e mesmo assim, tem alguns filmes por exemplo que eu não conheço ou que eu só ouvir e não as sistir de fato, mas que o livro didático traz essa contribuição no acrescentar, nessa minha prática pedagógica. (Profess or X).
}

O livro assim, demonstra ao professor a existência de outras mídias que o podem auxiliar no momento da aula, como o professor $\mathrm{X}$ aponta. Os livros didáticos sugerem filmes que os professores muitas vezes não conhecem ou que já ouviram falar, mas que não haviam ligado ao conteúdo. Mesmo com uma prática cotidiana de assistir filme, o que notamos é uma separação entre o sujeito espectador fora da escola e da sala de aula e, o sujeito professor utilizador de filmes em sala.

Identificamos essa separação de sujeitos na fala do professor VII. Uma prática diferente de assistir filmes no cinema ou em outros espaços fora da escola. No entendimento do professor, o sujeito fora da sala de aula assiste ao filme pelo lazer, pelo entretenimento, permite que os sentimentos em torno da emoção venham à tona, mas na escola, o filme é visto do ponto de vista profissional/didático e o professor aponta que este é o reforço que as sugestões dos livros didáticos trazem a sua prática.

Alguns professores também relataram que os alunos pedem para que o filme seja exibido em sala de aula e comentem sobre filmes que viram fora da escola, correlacionando com o conteúdo que o professor está trabalhando naquele momento. Isso ocorre porque o aluno 
também tem acesso às sugestões em alguns livros didáticos. Por isso é importante que as sugestões apareçam também para os alunos e não apenas nos manuais dos professores.

[...] eu vou citando a partir dos conteúdos que a gente vai vendo eu vou citando pra (sic) eles, porque caso eles queiram e tenham, alguns até as sistemou já assistiram "ah professora eu já assistir, é mesmo". Ai a gente faz aquele feedback com o que ele assistiu e com o conteúdo. (Professor V).

Apesar do conhecimento e de atribuir significativa importância e contribuição das sugestões para a prática docente, as sugestões de filmes trazidas pelo livro didático ainda não são muito utilizadas pelos professores. Muitos afirmam que preferem trazer filmes do seu próprio acervo cultural e que já possui certa experiência com tais filmes ligados aos conteúdos que trabalham em cada ano do ensino fundamental.

Confesso a você que nem sempre eu olho, nem sempre. Eu vou pelo que eu conheço. Então as vezes, quando eu to (sic) as sim, num (sic) conteúdo que eu não tenho muito conhecimento, assim, não me lembro muito de filmes que tem relação, aí eu vou lá e dou uma olhadinha, dou uma catadazinha (sic), mas geralmente eu vou pelos livros, pelos filmes que eu conheço. Porque eu já tive uma experiência não muito agradável de passar um filme que foi sugerido, mas que eu não conhecia e houveram algumas reclamações de alunos então eu preferir não mais usar filmes que eu não tenha tido a chance de as sistir primeiro. (Professora V).

Comparando as falas dos professores com as respostas coletadas por meio do questionário, percebemos que os dados são muito próximos, como demonstramos no gráfico 1 . Não há muita utilização das sugestões. Mas encontramos uma utilização significativa de filmes que não são sugeridos pelo livro, que o professor leva mais em consideração pelas experiênc ias pedagógicas que possui com determinada obra cinematográfica. 
Gráfico 1 - Frequência de uso das mídias em sala de aula

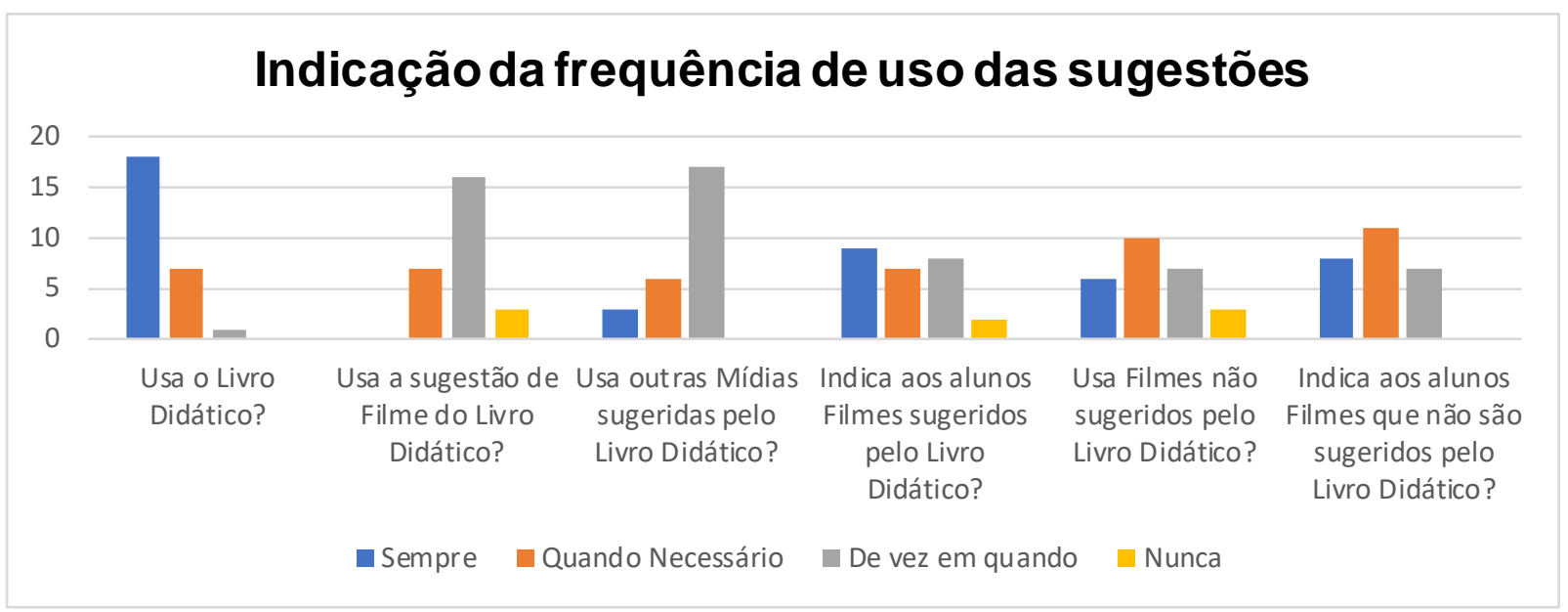

Fonte: Questionário aplicado pelo pesquisador (2019).

Podemos observar também que os professores atribuem muita importância ao livro didático em suas práticas, tendo papel de destaque no cotidiano docente e do aluno. Já as sugestões de filmes são usadas de vez em quando, sendo que o professor sugere mais que ele veja em casa. Mas transferir o uso das sugestões para fora da escola, onde o aluno não terá o professor para atender as suas dúvidas e auxiliar na compreensão do filme pode acabar desvirtuando a mensagem da narrativa. Por mais que os professores indiquem que a sugestão do filme no livro didático contribuía para a sua prática docente, percebemos que ainda há muito trabalho em torno de uma utilização mais efetiva destas sugestões.

É interessante que o filme seja visto com o professor. Se visto em casa, que haja discussão em sala de aula. Isso contribui para que se construa significado do filme para o aluno em torno dos preceitos históricos ditos necessários para a sua formação. E percebemos que os professores procuram ao máximo deter o controle dos filmes e do conteúdo que são usados em sala de aula ou sugeridos para ver em casa.

[...] tem que ser um filme que tenha alguma qualidade, que não seja longo né, que tenha um enredo, que tenha alguma ação, alguma animação, que hoje os recursos são ilimitados praticamente né, tem filmes que são, que tem ação, então, o que eles gostam né, atrai, segura a atenção do aluno, assim, muito longo, cheio de depoimentos não dá certo, não dá certo. Entrevista, não dá certo. A não serque, seja uma entrevista muito bem produzida, uma pessoa muito assim comunicativa, assim, extrovertida talvez, mas de outra forma não dá certo. (Profes sor IV).

Eu não exibo filme nenhum que eu não tenha assistido, primeiro é isso. Segundo, ele tem que ser correto historicamente, eu não vou passarum filme que é de história que ele não seja, que ele conta ao meu ver, inverdades ou diferentes percepções do real que não é a minha. Terceiro, ele tem que ter as qualidades de um filme, ele tem a estética, ele tem que ter né, o ritmo de um filme, porque por exemplo, não dá pra (sic) eu passar um filme muito lento, muito vamos dizer assim intelectual para o pessoal, eles precisam de uma coisa (estalos de dedos) pro (sic) pessoaldo EJA à noite, se não 
eles vão dormir ali. Eu preciso de uma coisa (estalos de dedo) mais rápida, que misture crítica (Profes sor VII).

As afirmações nos permitem inferir que os professores não passam o filme pelo filme. Há um processo de preparação, de estudo sobre o filme, investigando todas as formas possíveis de contribuição do filme com o processo de ensino e aprendizagem. No entanto, também está claro que o filme apenas alimenta e reforça o conteúdo, significando uma extensão de forma imagética trabalhada pelo professor e pelo livro didático.

Se compreende relativamente o tempo de aula (50 minutos). Assim, o professor de história deve tentar ao máximo abordar outras questões do filme. Até mesmo o lado técnico/artístico do filme (a iluminação, a atuação, a câmera, etc.) podem contribuir para a construção de uma visão histórica mais interessante.

No entanto, até mesmo quando os professores trabalham com alguns elementos técnico/artístico, eles são voltados e correlacionados estritamente ao conteúdo. Podemos observar na fala de alguns professores, que a fotografia, o cenário, o figurino, a lingua gem, entre outros também são preocupações do direcionamento do olhar pedagógico sob a obra, mas apenas para que o aluno perceba em forma de imagem e movimento, como os sujeitos do período histórico do conteúdo tratado comportavam-se e relacionavam-se em determinada época.

Então, eu, hoje eu to (sic) vendo is so. Primeiro o conteúdo. Como o filme é abordado, se ta (sic) adequado, se a linguagem histórica dele ta (sic) adequada, mas de um tempo pra cá (sic) eu tenho percebido, assim, tenho muito conversado de um tempo pra cá (sic), que eu tenho escolhido também filmes usando, não só esse critério, mas junto desse critério, eu vejo a fotografia, como a qualidade do filme ta (sic) sendo produzida. (Profes sor IX).

Apesar dos professores enxergarem nas sugestões uma grande contribuição para a sua prática, alertam que elas não se adequam ao tempo curricular da disciplina de história. Mesmo que em alguns momentos possuam dois horários, um após o outro, não conseguem explorar a obra da forma que quer.

E tem alguns que são longos, você, eu não sei se existe, mas você tinha que fazer certos cortes neles, porque a gente só tem uma aula de 50 minutos e tem deles que são longos e não da pra (sic) passar no horário de 50 minutos, a não ser que seja horários germinados, duas aulas seguidas, pra gente poder fazer os cortes né, tirar aquilo que é aces sório pra poder a gente pas sar dentro do nos so horário de aula. (Professor III).

As dificuldades são, as dificuldades são tempo, esse modelo de aula de 50 minutos é extremamente complicado pra (sic) gente que trabalha com filme, porque o filme tem o que? Tem 120 minutos né? Então é muito difícil. Quando você tem duas aulas ainda não dá, porque você ainda vai montar o equipamento, a gente não tem o espaço, aí você acaba pedindo a aula de um colega né. (Professor VII). 
Alguns livros didáticos procuraram de alguma forma colaborar com o planejamento das aulas e com o trabalho docente. Em suas sugestões, já abordam os trechos do filme que o professor pode apontar junto aos alunos, quais são as principais características que podem ser levadas em consideração e ainda propõem quais questões podem nortear o debate em torno das particularidades do filme. O livro delimita bem no filme o seu espaço/tempo de produção e as contribuições que podem oferecer para tal conteúdo. No entanto, apenas a coleção Araribá traz em sua organização de sugestões um trabalho mais minucioso de adequação do filme a realidade da sala de aula.

Outras coleções apenas trazem as sugestões junto a pequenas sinopses e informações básicas do filme, mas não traz uma análise precisa de como o filme pode contribuir para o trabalho docente em sala de aula. Quando o livro didático preocupa-se em construir uma análise filmica, ele não está diminuindo o trabalhado do professor, mas sim, colaborando para uma prática mais efetiva. Isso também demonstra que há uma certa compreensão que o tempo do professor é curto, devido a elementos da vida pessoal, de outros vínculos empregatícios, etc. Quando a sugestão já vem com as principais características do filme, auxilia o professor em seu momento de planejamento, tanto de aula quanto do uso da sugestão em sala de aula.

Na prática, os professores preferem passar o filme completo, já outros preferem exibir os trechos mais importantes para aquele conteúdo. E todas essas práticas são validas. O filme completo ou não, existe a necessidade de "dirigir um pouco o olhar do aluno, a fim de que a atividade seja mais produtiva" (MACHADO, 2015. p. 61). Claro que o filme completo permite que outras discussões sejam geradas. Mas diante da realidade das aulas de história, os filmes acabam que sendo cortados para poderem ser melhor aproveitados.

\footnotetext{
Não, eu prefiro passar todo e sem contar que eles também cobram isso, entendeu? "Não professor, vamo (sic) assistir o filme todo"e eu acho interessante também, pra (sic) prender mesmo a atenção deles, o objetivo também é esse, da gente fazer com que eles prestem atenção bastante e se você ficar passando eles não vão entender, da questão da história e eu gosto de passar completo, completo. (Professor II).
}

Observamos que há poucas sugestões de curta metragens para os conteúdos de história ou para trabalhos interdisciplinares, demonstrados na tabela 1. Isso nos mostra que há pouca preocupação das editoras em sugerir obras que possam ser usadas de fato em sala de aula. Cerca de $80 \%$ das sugestões de filmes não podem ser exibidas de forma completa. E quando o livro didático não aponta para o professor como ele pode utilizar o filme, deixa o trabalho do professor redobrado. 
Tabela 1 - Número de sugestões longa e curta-metragem

\begin{tabular}{cc}
\hline Longa-Metragem & Curta-Metragem \\
\hline 225 sugestões & 20 sugestões \\
\hline
\end{tabular}

Fonte: Coleções de livros didático utilizados na rede de ensino do estudo (2019).

Há sugestões que chegam a ter mais de 05 horas de duração, a exemplo do filme "Cleópatra" (Joseph Mankiewicz, 1963). Como trabalhar com um filme tão extenso em sua amplitude? O aluno fica na escola durante 04 horas e 30 minutos, correspondente ao turno que estuda. No livro, a sugestão apenas apresenta um resumo da obra, mas não aponta como os professores poderiam trabalhar com uma obra tão vasta em sala de aula e também não diz muito sobre o filme.

Para tentar auxiliar o professor na compreensão da importância do cinema para a história, os livros didáticos abordam os conceitos e as discussões que estão em torno do uso de filmes na disciplina e quais são as relações e contribuição do filme em sala de aula. Os textos trabalhados pelos livros estão em pleno acordo com as ideias e teorias construídas por pesquisadores que dedicam seus trabalhos a compreender as possiblidades do cinema em sala de aula. Ferro (1992) afirma que o filme é um produto do seu tempo e o representa muito mais que a própria narrativa busca tratar. Machado (2015) também nos alerta que, independente se o filme é de ficção ou documentário, se o professor estabelecer bem as regras de uso em sala de aula e dominar os dispositivos necessários, pode revelar o que está oculto ou subentendido no filme, como também aponta o material do livro didático.

Para Lipovetsky (2009) o filme tanto consente que o presente julgue o passado como também os meios para relatar os fatos históricos, ou seja, permite uma problematização do passado contado. E percebemos que os professores têm esse entendimento da sétima arte. Por mais que a principal característica que procurem nos filmes seja a sua ligação com o conteúdo, preocupam-se muito com os elementos históricos que são tratados pelo filme e pela sua coerência. Não exibem de forma alguma, nenhum filme que não se correlacione de forma correta no tratamento do fato histórico ou que não tenham assistido antes, usando principalmente a sua formação universitária e sua experiência docente como parâmetros de análise dos filmes e do seu uso em sala de aula. 
Então por exemplo, tem certos documentários que são muito bons no ponto de vista da qualidade técnica e também de conteúdo, mas pra (sic) um adolescente ele é maçante, a gente tem que pensarno outro, não é pensar, por exemplo, eu gosto muito de vídeos nesse, de documentário. Mas meu aluno é um adolescente, como é que ele vai ver es se vídeo? Então as sim, a gente tem que ter acompanhamento, nós, agora com o nosso estagiário, expomos alguns na sala de aula que teve tempo pra (sic) debater. Era vídeos de dez, vinte minutos. Agora alguns filmes, alguns são filmes do âmbito comercial, então são longos. (Profes sor IV).

Outra característica importante que destacamos nas entrevistas é que apenas um professor apontou sua preferência por filmes nacionais, afirmando enxergar nestes filmes uma aproximação maior entre aluno e conteúdo quando o filme é brasileiro. E isso é interessante, pois não é só do conteúdo que estamos falando, mas também de uma identificação cultural com a obra. Um filme nacional pode transmitir muito mais valores da nossa cultura do que sugestões internacionais.

E o que eu percebi, que eu faço questão na escola já a muitos (sic) anos, tanto que a nossa escola teve até esse projeto de cinema a noite né, que foi motivo do desfile 7 de setembro no ano de desse na rua de Bahia né, então a gente da opção mesmo, quando eu estava lá a noite, que eu tive que sair da escola, a gente da opção pelo filme, o filme nacional, que eu acho que tem eu uma identificação, eles compreendem, ficam mais simples pra (sic) eles né. (Professor VII).

No Brasil a lei $\mathrm{n}^{\mathrm{o}} 13.006$ de 26 de junho de 2014 acrescenta ao artigo 26 da lei $\mathrm{n}^{\circ} 9.394$, de 20 de dezembro de 1996 o seguinte: “A exibição de filmes de produção nacional constituirá componente curricular complementar integrado à proposta pedagógica da escola, sendo a sua exibição obrigatória por, no mínimo, 2 (duas) horas mensais. No entanto, há livros inteiros que não há uma sugestão sequer de filmes brasileiros, a exemplo do livro "Estudar História- das origens do homem à era digital" para o $6^{\circ}$ ano, enquanto isso, dos dez filmes sugeridos, sete são hollywoodianos.

Não questionamos se o professor tinha conhecimento ou não da lei, mas é de grande importância o projeto desenvolvido por ele em sua escola para a disseminação dos filmes nacionais. Os filmes podem contribuir muito para uma formação cultural ampla. Com uma identificação cultural mais próxima, essas contribuições podem ser desenvolvidas de forma mais significativa.

Segundo Machado (2015) a disciplina de história tem como foco o desenvolvimento de certa autonomia do aluno diante dos fatos históricos. Ou seja, a construção de um sujeito crítico e pensante mediante as informações compartilhadas de diversas formas em seu entorno. E para isso, o autor alerta que os filmes podem contribuir significativamente para esta formação.

Por outro lado, essa disciplina possui características conteudísticas muito fortes. O diálogo é muito presente como forma de transmissão do conhecimento que o professor tem para 
os alunos que estão presentes em sala de aula (DUARTE, 2009). O que percebemos é que com o filme não é muito diferente. Alguns professores exibem os filmes com curtas pausas para apontar o que quer mostrar no filme de acordo com o conteúdo.

Olhe, em relação a filmes, como eu te falei anteriormente, eu procuro usar assim, filmes simples, curtos né, e as vezes dou um play, explico um pouquinho, porque pra (sic) eles acompanharem, pra (sic) eles irem pelo enredo, pela his tória, irem fazer uma correlação com o conteúdo, mais ou menos nesse sentindo. (Professor I).

Os professores apontaram que o meio ou o fim da abordagem do conteúdo é o melhor momento para exibir um filme em sala de aula. Afirmam que o conteúdo sempre vem em primeiro lugar, para depois então, finalizar o trabalho do assunto com a discussão do filme. Essa metodologia baseia-se no domínio dos fatos por parte do aluno, para que a discussão possa ser ampliada e melhor aproveitada, já que os professores julgam que durante a aula, os alunos conseguiram compreender o conteúdo ou construir dúvidas que serão suscitadas com a obra.

\begin{abstract}
Então, normalmente os filmes eles vão, eles vão ou no fim ou no meio do conteúdo ne, ou pra (sic) amarrar o conteúdo ou no meio pra (sic) instigar a debate depois. Então como é o planejamento. Dou um pouco do conteúdo, dou uma orientação, o filme é passado, depois ou tem uma atividade que eu já preparo escrita pra (sic) eles responderem né, ou a gente debate o que eles acharam, o que eles não gostam, o que eles gostaram né, a gente tem essa atividade com as séries normais. (Professor VII).
\end{abstract}

Já outros professores creem que os alunos produzem mais em aula quando o filme é exibido antes do conteúdo. Aqui percebemos o filme como um dispositivo de apresentação do conteúdo. Os professores afirmam que, à medida que as abordagens vão avançado, os alunos vão lembrando das cenas, dos diálogos, dos cenários que foram tratados pelos livros, ampliando as discussões no momento da aula.

\footnotetext{
Assim, a gente primeiro, eu faço, eu gosto de fazer como se diz, o efeito contrário, como o contrário? Primeiro eu gosto de passar o filme e depois eu passar (sic) o conteúdo, entendeu? Já fiz também de passar o conteúdo e depois o filme, mas eu acredito que passando o filme e depois o conteúdo, na hora que você ta (sic) explicando lembra "oi ta (sic) lembrando daquela parte do filme" então, "retrata is so". (Professor II).
}

Encontramos nestas práticas, diversas formas de avaliação. O que elas têm em comum é a preocupação em estabelecer critérios claros para que possam identificar se ocorreu de fato aprendizagem ou não dos alunos. Como um dos professores afirmou, é obrigação do docente voltar quantas vezes for preciso para explicação do conteúdo, até que o aluno consiga compreender determinado conteúdo ou fato. E é a partir dos seus métodos avaliativos que eles detectam a contribuição ou interferência que o filme teve no processo cognitivo. 
Discuto com eles e aí peço, geralmente a avaliação ta (sic) vinculada a um relatório ou a um questionário. Eu prefiro um questionário, porque quando eu digo, vai ter questionário eles prestam mais atenção. (Professor VI).

Sim. A minha avaliação, eu tenho um processo assim, de, quando a gente termina de assistir ao filme eu começo sempre o bate papo, do que eles entenderam, do que eles perceberam do que foi dito na aula, se tinha alguma cois a vercom o que o filme tava (sic) mostrando, se eles conseguiram fazer essa ligação do que foi falado no filme com a aula que tinha sido dada, porque ai eu percebo, é nes sa hora que eu faço a avaliação, de como eles, se eles conseguiram compreender o que eu dis se com o que ele viu no filme. (Profes sor IX).

Não há também um padrão para as avaliações entre os professores. Alguns optam pelo questionário, outros por uma avaliação escrita, debates, preenchimento de ficha técnica, etc. Isso nos mostra a complexidade dos filmes nas aulas de história. Percebemos desta forma, o comprometimento que os professores têm com a formação intelectual e cultural dos alunos.

Assim destacamos que o filme é uma mídia de grande valia para o ensino de história. Com a premissa de sempre contar uma história e, de sua câmera capturar elementos de um corte da realidade em um determinado tempo e espaço da civilização humana, são inúmeras as contribuições que o filme pode oferecer ao processo de ensino e aprendizagem, na prática docente e na construção cognitiva do aluno.

\section{A guisa de conclusões}

Os filmes têm muito a contribuir para a prática docente e para a formação dos alunos. $\mathrm{E}$ os professores tomam cada vez mais conhecimento e consciência desse processo. Compreendem que a sociedade passa por transformações significativas e que é preciso acompanhar o modo com que o aluno do século XXI aprende, sem necessariamente abandonar as práticas tracionais que ainda funcionam.

Apresentamos aqui um corte da realidade que encontramos nas práticas docentes nas escolas públicas municipais de Aracaju. Neste sentindo, o estudo visa contribuir tanto para a prática docente como para chamar a atenção de órgãos públicos, para que direcionem mais recursos e investimentos para a educação pública. Não necessariamente só para os filmes, mas sim para os meios de comunicação de massa, para as tecnologias e mídias digitais que tanto moldam nossas atividades cotidianas.

Destacamos como mais importante neste estudo, o trabalho de levantamento dos livros didáticos e a busca por compreender a partir dos preceitos das ciências sociais as contribuições que as sugestões de filmes podem trazer para a prática de ensino de história e como os professores estão atuando diante desta realidade. 
Nessa perspectiva, o estudo foi direcionado para responder à questão de como os professores usam os filmes sugeridos nos livros didáticos e como poderiam contribuir no fazer docente. Apesar de não termos encontrado uma prática relevante do uso destas sugestões, o objetivo geral de analisar o uso dos filmes sugeridos foi contemplado. Também percebemos que os filmes compõem a prática dos professores, fortalecendo nossa suposição de que os professores usam a sétima arte em suas aulas.

Partindo da premissa de que os filmes e a história possuem uma relação intrínseca, focamos no uso de filmes na disciplina pois é ela, a base para a construção das narrativas construídas pelas obras cinematográficas, onde encontramos um número recorrente de adaptações cinematográficas de fatos e eventos históricos presentes na história da humanidade.

Desta forma, este artigo reforça a necessidade de olharmos com mais atenção para as produções cinematográficas. Sejam elas de ficção, documentais históricos ou não, de grande circulação ou produções independentes, os filmes têm muito para dialogar com a educação e com o ensino de história. Os filmes são produções que permeiam nosso cotidiano a mais de um século e tornou-se quase que impossível negar a sua influência e participação na formação de qualquer sujeito, principalmente quando estamos tratando do século XXI.

\section{Referências}

ANDRÉ, Marli. O que é um estudo de caso qualitativo em educação? Revista da FAEEBAEducação e Contemporaneidade, v. 22, n.40, p. 95-103, jul/dez. 2013.

ALMEIDA, M. J. de. Imagens e Sons: a Nova Cultura Oral. ed. 1. São Paulo: Cortez, 1994.

BRIGGS, A. e BURKE, P. Uma história social da mídia: de Gutenberg à Internet. Rio de Janeiro: Jorge Zahar, 2006.

CARVALHO, D. B. N. ANDRADE, L. R. S. LINHARES, R. N. LIMA, R. D. FREIRE, V. P. O uso dos filmes na formação inicial de professores de história: um estudo de caso. In. Challenges 2015: Meio século de TIC na educação, 2015, Braga, Portugal. Anais.

Universidade do Minho, Centro de Competência em TIC na Educação, 2015.

Disponível em: http:/www.nonio.uminho.pt/challenges/download/atas-challenges-2015/ Acesso em 04/11/2018.

COSTA, Antônio Pedro; AMADO, João. Análise de conteúdo suporta por software. Revista Lusófona de Educação, v. 41, n. 1, p. 241-243. Nov. 2018.

DUARTE, R. Cinema e Educação. Belo Horizonte: Autêntica Editora, 2009.

FERRO, M. Cinema e História. Rio de Janeiro, RJ: Paz e Terra, 1992. 
LINHARES, R. N.Gestão em comunicação e educação: o audiovisual no espaço escolar. Maceió: edufal, 2007.

LIPOVETSKY, G. A tela global: mídias culturais e cinema na era hipermoderna. Porto Alegre, RS: Sulina, 2009.

MACHADO, A. V. Filmes históricos no ensino de história. - Jundiaí, SP: Paco Editorial, 2015.

MARTIN, M. A Linguagem Cinematográfica. - São Paulo: Brasiliense, 2013.

MEIRINHOS, Manuel; OSÓRIO, António. O estudo de caso como estratégia de investigação em educação. Eduser- Revista de Educação, v.2, n.2. 2010.

MINAYO, Maria Cecîlia de Souza. Fundamentos, Percalços e Expansão das Abordagens Qualitativas. In SOUZA, Dayse Neri; COSTA, Antônio Pedro; SOUZA, Francislê Neri. Investigação qualitativa: Inovação, Dilemas e Desafios. Fortaleza: Ludomedia. 2016.

NUNES, A. K. F. Políticas públicas e TIC na educação: DITE Sergipe 1994 a 2007. Aracaju, SE: EDUNIT, 2015.

OLIVEIRA, M. M. de. Comofazer pesquisa qualitativa. Petrópolis, RJ: Vozes, 2008.

ROSENSTONE, R. A. A história nos filmes, os filmes na história. Tradução Marcello Lino$2^{\circ}$ ed.- Rio de Janeiro, Paz e Terra, 2015.

SANTOS, M. G. M. Gestão das TIC nas escolas municipais de Aracaju na percepção dos diretores. 2016. 115 p. Dissertação (Mestrado em Educação) - Universidade Tiradentes, 2016.

SETTON, M. G. Mídia e Educação. São Paulo: Contexto, 2010.

YIN, Robert K. (2005). Estudo de caso: planejamento e métodos. Porto Alegre: Bookman. 